\title{
INOVASI VIRTUAL LAB SEBAGAI MEDIA PEMBELAJARAN DI SMP DAN SMK ISLAM ASY'ARIYYAH IBRU KECAMATAN MESTONG
}

\author{
Sri Purwaningsih'1), Rahma Dani'1), Neneng Lestari'1), Edy Yuversa ${ }^{1)}$ \\ 1)Jurusan PMIPA Program Studi Pendidikan Fisika, FKIP, Universitas Jambi, Jambi, Indonesia \\ Corresponding author: Sri Purwaningsih \\ E-mail : sripurwaningsih@unja.ac.id
}

Diterima 30 November 2021, Disetujui 05 Desember 2021

\begin{abstract}
ABSTRAK
Penggunaan media pembelajaran yang berbasis virtual lab sangat minim digunakan di sekolah, hal ini disebabkan para guru belum mengetahuinya, terutama di SMP Islam Asy'Ariyyah dan SMK Islam Asy'Ariyyah Kecamatan Mestong Muaro Jambi yang menyebabkan kurang optimalnya proses pembelajaran fisika di kedua jenjang pendidikan sekolah tersebut. Pengabdian kepada masyarakat ini memiliki tujuan untuk mendemonstrikan penerapan dan mengadakan pelatihan kepada guru-guru di sekolah tersebut dengan membuat media pembelajaran yang berbasis virtual lab yang telah didesain oleh dosen di lab fisika FKIP universitas Jambi. Pelaksanaan pengabdian pada masyarakat ini terdiri dari beberapa tahap yaitu studi pendahuluan yang terkait dengan analisis situasi di sekolah dan analisis permasalahan mitra, diantaranya adalah kurangnya pengetahuan guru membuat dan pengguanaan media pembelajaran yang berbasis virtual lab. Program dilakukan adalah demonstrasi, workshop dan membuat media pembejaran berbasis virtual lab. Dari hasil pengabdian ini diperoleh tanggapan dari guru bahwa guru sangat antusias mengikuti program yang telah dilaksanakan, guru telah dapat menggunakan virtual lab.
\end{abstract}

Kata kunci: virtual lab; SMP islam asy'ariyyah; SMK islam asy'ariyyah.

\begin{abstract}
The use of virtual lab-based learning media is very minimal in use in schools, this is because teachers do not know it, especially in Asy'Ariyyah Islamic Junior High School and Asy'Ariyyah Islamic Vocational School, Mestong Muaro Jambi District which causes the physics learning process to be less than optimal at both levels of school education. This community service has the aim of demonstrating the application and providing training to teachers at the school by creating learning media based on virtual labs that have been designed by lecturers at the physics lab of the Faculty of Teacher Training and Education, Jambi University. The implementation of community service consists of several stages, namely preliminary studies related to situation analysis in schools and analysis of partner problems, including the lack of knowledge of teachers in making and using virtual lab-based learning media. The programs carried out are demonstrations, workshops and making learning media based on virtual labs. From the results of this service, a response was obtained from the teacher that the teacher was very enthusiastic about participating in the program that had been implemented, the teacher had been able to use the virtual lab.
\end{abstract}

Keywords: virtual lab; asy'ariyyah islamic junior high school; asy'ariyyah islamic vocational school.

\section{PENDAHULUAN}

Mestong merupakan salah satu kecamatan di kabupaten muaro jambi Provinsi Jambi, Indonesia yang secara geografis merupakan kecamatan yang masih tergolong dekat dengan kota jambi, kendati demikian kecamatan mestong masih tergolong kecamatan yang terisolir sehingga dalam pelaksanaan pembelajaran di sekolah belum banyak memanfaatkan teknolagi sehingga proses pembelajaran menjadi kurang menarik, terutama di terutama di SMP Islam Asy'Ariyyah dan SMK Islam Asy'Ariyyah Kecamatan
Mestong Muaro Jambi. Padahal banyak sekali software dan IT yang dapat digunakan untuk membuat media pembelajaran agar proses pembelajaran dapat terlaksana menjadi lebih menarik. Dari observasi dan wawancara yang telah dilakukan dengan guru-guru di sekolah tersebut diperoleh data bahwa proses pembelajaran di kelas kurang optimal, belum adanya media pembelajaran yang berbasis virtual lab dalam pembelajaran sehingga pembelajaran menjadi kurang menarik dan sulit dipahami. Terutama pada saat pandemi covid 19 sekarang ini, sudah seharusnya guru-guru 
menggunakan media pembelajaran yang berbasis virtual lab sehingga siswa dapat belajar mandiri di rumah. Virtual lab merupakan serangkaian alat labor yang berbentuk perangkat lunak berbasis multimedia interaktif, yang dioprasikan dengan komputer dan dapat mensimulasikan kegiatan belajar di laboratorium seakan user berada pada laboratorium real. Laboratorium virtual merupakan suatu produk unggul hasil kemajuan teknologi informasi dan laboratorium, pembelajaran dengan menggunakan laboratorium virtual dapat dijadikan sebagai alternatif pengganti untuk mengeliminasi keterbatasan perangkat laboratorium (Wegener dkk., 2012). Akan tetapi karena kekurangpengetahuan guru dalam menggunakan media pembelajaran yang berbasis virtual lab ini dapat membuat pelaksanaan pembelajaran menjadi kurang optimal. ketersediaannya media pembelajaran yang berbasis virtual lab di sekolah yang berfungsi memudahkan siswa memahami pembelajaran hal inilah yang mendorong dosen pendidikan fisika melakukan penelitian pengembangan berupa desain media pembelajaran berbasis virtual lab yang merupakan salah satu hasil penelitian dosen pendidikan fisika Universitas Jambi yang dapat digunakan untuk mempermudahkan siswa dalam pembelajaran dimanapun berada. Hal ini sejalan dengan ungkapan Gunawan dkk. (2012) bahwa virtual lab dapat mempermudah siswa belajar dan memahami materi percobaan. Berdasarkan hal tersebut sangat diperlukan upaya untuk memperkenalkan dan memberi pelatihan pada para guru di sekolah mengingat media tersebut sangat penting digunakan dalam pembelajaran.

\section{METODE}

Metode yang digunakan dalam kegiatan ini adalah demonstrasi, penyuluhan, diskusi, pelatihan dan praktek yang disampaikan oleh Tim pengabdian kepada guru-guru SMP Islam Asy'Ariyyah dan SMK Islam Asy'Ariyyah, kegiatan ini dilaksanakan pada Tanggal 11 September 2021, adapun tahap-tahapnya adalah sebagai berikut:

\section{a.Tahap Persiapan}

Tahap persiapan yang dilakukan untuk melaksanakan program ini meliputi

1. Melaksanakan observasi ke 666 tempat pelaksanaan kegiatan.

2. Pembuatan proposal dan menyelesaikan administrasi perizinan pada instansi yang akan dilibatkan pada pelaksanaan kegiatan.
3. Persiapan perlengkapan kegiatan pelatihan (Alat dan bahan pelatihan berupa software Adove Flash CS 5)

4. Menginstal software tersebut ke Labtop guru-guru SMP Islam Asy'Ariyyah dan SMK Islam Asy'Ariyyah seminggu sebelum kegiatan dimulai.

\section{b.Tahap Pelaksanaan Kegiatan}

Pelaksanaan kegiatan ini dilakukan pada hari sabtu tanggal 11 September 2021 jam 09.00 13.00 WIB, yang meliputi:

1. Registrasi peserta.

2. Pembukaan, kegiatan pelatihan ini dibuka oleh ketua pelaksanaan pengabdian diikuti oleh kata sambutan dari Kepala SMP Islam Asy'Ariyyah. Dilakukan penyebaran angket kepada guru-guru untuk mengetahui pengetahuan awal guru-guru tentang pengenalan virtual lab. Tim pengabdian melaksanakan workshop dilakukan dengan penyampaian materi tentang pengenalan virtual lab, media pembelajaran, demontrasi virtual lab yang telah didesain, menjelaskan bagaimana tahap-tahap dalam pembuatan virtual lab berbasis adove flash CS 5 . Menurut Yusuf dkk., (2015) bahwa pengembagan media lab virtual dilakukan menggunakan aplikasi Adobe Flash CS 6. Tahap pertama yang dilakukan adalah pengembangan model media (pra produksi). Pekerjaan yang di-lakukan pada tahap ini meliputi penentuan navigasi, pemilihan warna latar, serta penentuan materi, animasi, contoh soal, dan konsep yang akan dimasukkan dalam media. Guru menyimak dan memperhatikan materi yang disampaikan dalam workshop tersebut, selanjutnya dilakukan diskusi dan tanya jawab. Pada kegiatan workshop ini guru sangat antusias dan bersemangat dalam mengikutinya, hal ini terlihat dari berbagai pertenyaan yang disampaikan ketika acara berlangsung, rasa ingin tahu sangat tinggi, tim pengabdian sangat memberi apresiasi terhadap sambutan mereka dalam mengikuti acara kegiatan ini, hal ini dapat dilihat pada Gambar 1 di bawah ini

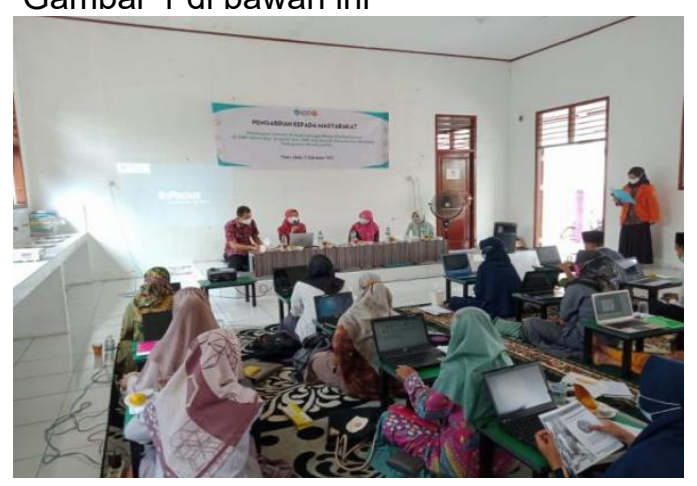

Gambar 1 : Kegiatan workshop sedang berlangsung di sekolah 
Pada Gambar 1 di atas terlihat bahwa tim pengabdian sedang melaksanakan penyampaian materi pentingnya media pembelajaran serta manfaat media pembelajaran pada kegiatan workshop yang sedang berlangsung. Selanjutnya diikuti penyampaian materi tentang pengenal virtul lab, hal ini dapat dilihat pada gambar 2 di bawah ini

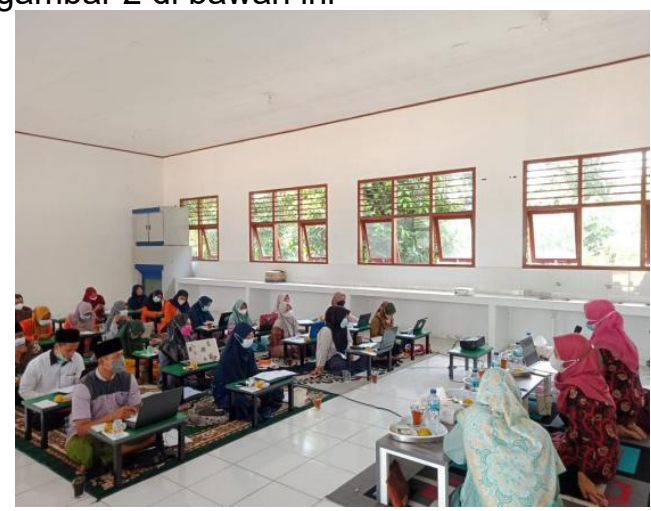

Gambar 2 : penyampaian materi tentang pengenalan virtual lab

3. Melaksanakan pelatihan yaitu guru-guru dilatih dalam pembuatan virtual lab, masing-masing guru bekerja pada labtop yang telah terinstall adove flash CS5, sehingga guru-guru dapat mendesain virtual lab yang telah diarahkan oleh tim pengabdian. Setelah guru mendapat arahan dari tim pengabdian, dilanjutkan mengerjakan tugas secara bersama di labtop masing-masing, hal in dapat dilihat pada Gambar 3 di bawah ini.

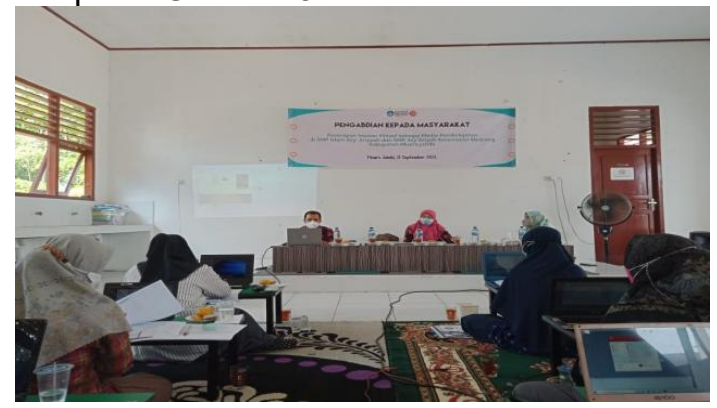

Gambar 3: pelatihan pembuatan media pembelajaran virtual lab.

Dari Gambar 3 di atas terlihat guru-guru sedang membuat media pembelajaran virtual lab, guru-guru sangat antusias mengikuti kegiatan ini, hal ini terlihat ketika diskusi, tanya jawab dan bimbingan selama kegiatan pelatihan berlangsung. Guru-guru sangat aktif dan tekun dalam mempelajari software flash, guru diberi arahan setiap langkah-langkah pengerjaan virtual lab dengan menggunakan software flash. Sejalan dengan itu bahwa pemanfaatan bahan ajar yang dikemas dalam bentuk virtual laboratory dapat meningkatkan kualitas pendidikan. Oleh karena itu, guru hendaknya mampu berinovasi dan berkreasi dalam rangka merancang suatu pembelajaran yang menarik dan bermakna bagi siswa (Khaira dkk., 2017). mengingat guru dituntut berinovasi dab berkreasi dalam mendesain media pembelajaran, maka guru yang sedang pelatihan sangat antusias dalam mempelajari tahap-tahap mendesain virtual lab.

\section{c. Tahap akhir}

Tahap akhir kegiatan ini terdiri dari penutupan kegiatan pelatihan oleh ketua pelaksanaan pengabdian, diakhiri berfoto bersama antara guru-guru, kepala sekolah, ketua yayasan Asy'Ariyyah dan tim pengabdian serta pemberian kenang-kenangan dari pihak tim pengabdian ke pihak sekolah dan sebaliknya. Hal ini dapat dilihat pada Gambar di bawah ini

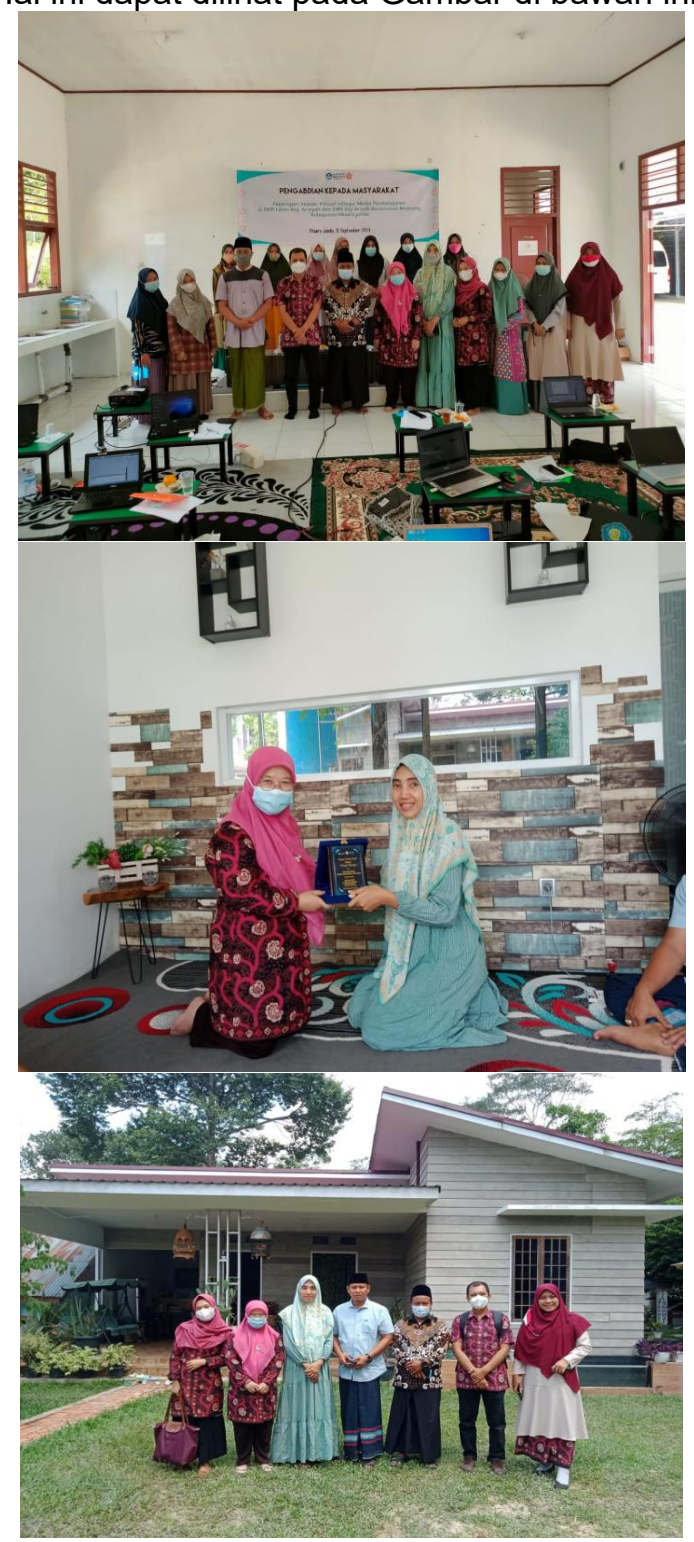

Gambar 4: Penutupan kegiatan pelatihan dan pemberian kenang-kenangan. 
Tahap selanjutnya adalah pembuatan laporan hasil kegiatan dan pengumpulan laporan hasil kegiatan ke Lembaga pengabdian kepada masyarakat Universitas Jambi.

\section{HASIL DAN PEMBAHASAN}

Dari hasil penyebaran angket yang diberikan kepada guru-guru, terlihat bahwa ternyata guru-guru sangat antusias dalam melaksanakan kegiatan tersebut. Dari hasil wawancara melalui angket yang telah disebarkan juga terlihat bahwa selama ini guruguru belum pernah mengenal virtual lab, guruguru juga belum pernah belajar virtual lab, serta guru-guru belum pernah menggunakan virtual lab. Dengan adanya kegiatan pelatihan ini, ternyata dapat memberi wawasan dan pengetahuan baru bagi para guru SMP Islam Asy'Ariyyah, SMK Islam Asy'Ariyyah tersebut, manfaatnya sangat dirasakan oleh guru. Para guru sangat terarik dalam mengikuti kegiatan pelatihan, mereka akan menggunakan virtual lab untuk mengajar nantinya, Tim pengabdian memberikan tugas terkait dengan pembuatan media pembelajaran virtual lab berbasis flash CS 5 yang harus diberikan oleh guru-guru dalam kegiatan pelatihan ini.

Selain itu, dari hasil angket dan wawancara juga terungkap bahwa dengan menggunakan virtual lab, guru merasa mudah untuk memberi materi ajar kepada siswa, karena materi sudah dikemas melalui media tersebut. Guru-guru memiliki pengetahuan baru berkaitan dengan media virtual lab, sebab selama ini guru di sekolah tersebut belum pernah mendapatkan materi tentang virtual lab. Selain itu guru juga sangat berminat menggunakan virtual lab ketika mengajar. Selanjutnya banyak saran yang diberikan oleh guru diantaranya adalah pengabdian hendaknya dilakukan secara kontinyu sehingga dapat menambah materi baru bagi guru-guru, kegiatan pengabdian ini sangat bermanfaat bagi guru untuk menambah wawasan, diharapkan kepada dosen tetap semangat dalam membagikan ilmu yang sangat bermanfaat dalam dunia pendidikan, selain itu saran dari peserta adalah kegiatan pengbadian dapat berkelanjutan dengan materi-materi yang tetap berkaitan dengan proses kegiatan belajar mengajar. Ungkapan kepala sekolah juga menyatakan bahwa selama ini kegiatan pengabdian yang terkait dengan materi yang dapat mengingkatkan proses kegiatan pembelajaran belum pernah diberikan dari pihak manapun.

Dari hasil wawancara penulis dapat menyimpulkan para guru di sekolah Islam Asy'Arriyah ini sangat mengapresiasi adanya kegiatan pengabdian ini, yang dapat mengingkatkan proses kegiatan pembelajaran.

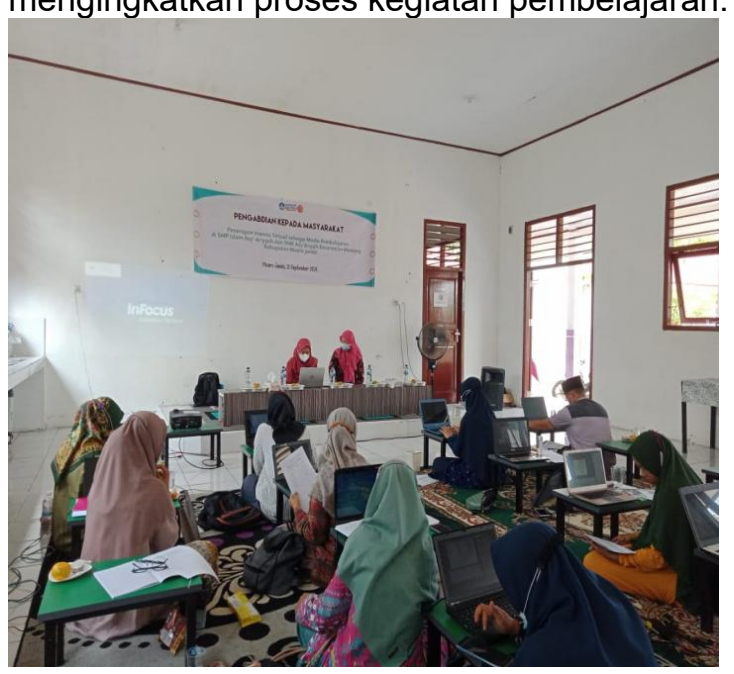

Gambar 5. kegiatan pengabdian sedang berlangsung, penyampaian materi pentingnya media pembelajaran

\section{SIMPULAN DAN SARAN}

Berdasarkan kegiatan pengabdian kepada masyarakat yang telah dilaksanakan dapat disimpulkan bahwa kegiatan pengabdian sangat dibutuhkan bagi pihak sekolah, dengan adanya kegiatan pengabdian ini guru-guru termotivasi dan dapat tambahan wawasan dalam menggunakan media pembelajaran virtual lab serta mendapat inspirasi bagi guru untuk membuat media pembelajaran virtual lab. Setelah melakukan kegiatan pelatihan pembuatan media pembelajaran virtual lab, guru-guru SMP Islam Asy'Ariyyah, SMK Islam Asy'Ariyyah sudah terlatih dalam membuat media pembelajaran. Perlu adanya media pembelajaran yang kreatif dan inovatif agar terciptanya suasana belajar yang menyenangkan. Diharapkan kepada pihak pemangku pendidikan diwilayah setempat dapat memberi perhatian terhadap sekolah agar memvasilitasi media pembelajaran yang inovatif.

\section{UCAPAN TERIMAKASIH}

Penulis mengucapkan terima kasih yang tak terhingga kepada pihak LPPM Universitas Jambi yang telah mendanai kegiata pengabdian dalam skim Penerapan Iptek.

\section{DAFTAR RUJUKAN}

Arifin, Z., (2010), Evaluasi Pembelajaran.UPI. Arsyad, Azhar. (2011). Media Pembelajaran. Jakarta: PT Raja Grafindo Persada.

Gunawan \& Liliasari.(2012). Model Virtual Laboratory Fisika Modern untuk Meningkatkan Disposisi Kritis Calon Guru. Cakrawala Pendidikan (No. 2. Tahun XXXI). 
Halliday, Resnick, Walker, (2011). Fundamental of Physics, 9th ed., John Wiley \& Sons Inc.

Khaira I., Maison, Jerfi Marsal, (2017). Pengembangan Perangkat Pembelajaran Fisika Berbasis Virtual Laboratorium Pada Materi Listrik Di SMK, Edu-Sains, Volume 6, No. 2. 2430.

Muarojambikab.bps.go.id. Kecamatan Mestong dalam angka 2019, Badang Pusat Statistik Kabupaten Muaro Jambi, diakses 5 Maret 2021. from https://muarojambikab.bps.go.id/publicat ion/2019/09/26/7d600eadfaf14ea62b1fe 334/kecamatan-mestong-dalam-angka2019.html.

Susilana, R. Ihsan, H. (2014). Pendekatan Saintifik Dalam Implementasi Kurikulum 2013 Berdasarkan Kajian Teori Psikologi Belajar. Edutech, Vol.1.No.2

Wijaya, C.A. Rusyan, T. (1994). Kemampuan Dasar Guru dalam Proses. Belajar Mengajar. Bandung: Remaja Rosda Karya.

Wegener M., T. J. Mcintyre, D.Mcgrath, C.M. Savage,\& M. Williamson, (2012). Developing a virtual physics world. Australasian Journal of Educational Technology, 28(3), 504-521.

Yusuf, I., Widyaningsih, S. W., \& Purwati, D. (2015). Pengembangan Perangkat Pembelajaran Fisika Modern Berbasis Media Laboratorium Virtual Berdasarkan Paradigma Pembelajaran Abad 21 dan Kurikulum 2013. Pancaran Pendidikan, 4(2), 189-200. 